\title{
Landslides detection in Bat Xat district, Lao Cai province, Vietnam using the Alos PalSAR time-series imagery by the SBAS method
}

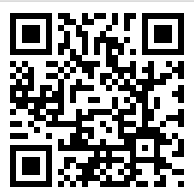

\author{
Anh Van Tran ${ }^{1,}$, Binh An Nguyen ${ }^{2}$, Tien Dinh ${ }^{3}$, Yen Hai Thi Nguyen ${ }^{4}$, Nghi Thanh Le ${ }^{1}$ \\ ${ }^{1}$ Faculty of Geomatics and Land Administration, Hanoi University of Mining and Geology, Vietnam \\ ${ }^{2}$ Hochiminh City Institute of Resources Geography, Vietnam \\ 3 Vimico - Lao Cai - Sin Quyen Copper Mine Branch, Vinacomin - Minirals Holding Corporation, Vietnam \\ ${ }^{4}$ Faculty of Surveying, Catography and GIS, Ho Chi Minh University of Natural Resources and Environment, \\ Vietnam
}

\section{ARTICLE INFO}

Article history:

Received 25 $5^{\text {th }}$ June 2020

Revised 03rd July 2020

Accepted 31st Aug. 2020

Keywords:

ALOS-PalSAR,

InSAR Radar,

Landslide,

Multi-temporal Radar,

SBAS.

\section{ABSTRACT}

Radar Interferometry (InSAR) has been known as a technology to monitor the change of elements on the earth's surface for many years. There are many InSAR methods, in which the permanent scattering InSAR Radar (PSInSAR) method uses a series of images to determine the terrain deformetions quite well. However, for areas with lots of vegetation, the number of permanent scattering points (PS points) will be limited. In this paper, we have chosen a method that also uses a set of multi-temporal Radar images but has the lowest spatial and temporal image baselines, this method is called the Small Baselines method (SBAS). With the ALOS PalSAR images series that was collected from August 2007 to November 2010, many landslide points in the area of Bat Xat district, Lao Cai province were discovered. The landslide locations detected from Radar images were compared with the landslide surveying points and landslide interpreted by aerial photos in 2013 provided by Vietnam Institute of Geosciences and Mineral Resources Vietnam. There have been many sliding sites coinsiding with the surveyed landslides, which proves that many landslides exist and develop continuously such as the location of Mong Sen bridge, Trung Chai Commune or at Sai Duan bridge, Phin Ngan commune.

Copyright (C) 2020 Hanoi University of Mining and Geology. All rights reserved.

${ }^{*}$ Corresponding author

E - mail: tranvananh@humg.edu.vn

DOI: 10.46326/JMES.2020.61(4).01 


\title{
Tạp chí Khoa học Kỹ thuật Mỏ - Địa chất
}

Trang điện tử: http://tapchi.humg.edu.vn

\section{Xác định trượt lở đất khu vực huyện Bát Xát, tỉnh Lào Cai sử dụng chuỗi ảnh Radar ALOS PalSAR bằng phương pháp đường đáy ngắn (SBAS)}

\author{
Trần Vân Anh ${ }^{1,}{ }^{*}$, Nguyễn An Bình ${ }^{2}$, Đinh Tiến ${ }^{3}$, Nguyễn Thị Hải Yến ${ }^{4}$, Lê Thanh Nghị ${ }^{1}$ \\ ${ }^{1}$ Khoa Trắc địa - Bản đồ và Quản lý đất đai , Trường Đại học Mỏ - Địa chất, Việt Nam \\ 2 Viện Địa lý Tài nguyên TP. Hồ Chí Minh, Việt Nam \\ ${ }^{3}$ Chi nhánh Mỏ tuyển đồng, Sin Quyền, Lào Cai - Vimico, Tổng Công ty Khoáng sản KTV, Việt Nam \\ ${ }^{4}$ Khoa Trắc địa, Bản đồ và GIS, Trường Đại học Tài nguyên và Môi trường TP. Hồ Chí Minh, Việt Nam
}

THÔNG TIN BÀI BÁO

\section{TÓM TẮT}

\section{Quá trình:}

Nhận bài 25/6/2020

Sưa xong 03/7/2020

Chấp nhận đăng 31/8/2020

Tù̀ khóa:

ALOS-PalSAR,

Radar đa thời gian,

Radar giao thoa,

SBAS,

Trượt lở đất.
Radar giao thoa được biết đến nhu một công nghệ để giám sát sự thay đổi các yếu tố trên bề mặt trái đất. Có khá nhiều phương pháp Radar giao thoa, trong đó phương pháp giao thoa Radar tán xa cố định (PSInSAR) sủ dụng một chuô̂i ảnh để xác định biến động địa hình khá tốt. Tuy nhiên, với khu vực có nhiều thực phủ thì số lương điểm tán xạ cố định thuờng bị hạn chế. Trong nghiên cúu này, nhóm tác giả lựa chọn phương pháp đường đáy ngắn (SBAS) với chuối ảnh đa thời gian ALOS PalSAR được thu trong khoảng thò̀i gian tù̀ tháng 8/2007 đến tháng 11/2010 để xác định trượt lở cho khu vực huyện Bát Xát và một phần nhỏ của huyện Sa Pa, tỉnh Lào Cai. Có nhiều điểm trượt lở đất ở khu vực nghiên cúu đã được phát hiẹn. Các vị trí trượt lở đất được phát hiên từ ảnh Radar đã đước so sánh với các điểm khảo sát trườt lở đất và điểm trượt lở đất giải đoán bằng ảnh hàng không năm 2013 do Viện Khoa học Địa chất và Khoáng sản Việt Nam cung cấp. Đã có nhiều vị trí trượt trùng với các điểm trượt lở được khảo sát, điều này đã chúng minh rằng có một số điểm trượt lở tồn tai và phát triển liên tục nhu vị trí cầu Móng Sến, xã Trung Chải hay tại cầu Sài Duẩn, xã Phìn Ngan.

C 2020 Trường Đại học Mỏ - Địa chất. Tất cả các quyền được bảo đảm.

\section{Mở đầu}

Tai biến địa chất hiện đại nói chung, tai biến trượt lở nói riêng đã và đang gây tổn thất to lớn về người và của cho nhiều quốc gia trên thế giới và đặc biệt ở các vùng miền núi của Việt Nam (Lê

*Tác giả liên hệ

E - mail: tranvananh@humg. edu.vn DOI: 10.46326/JMES.2020.61(4).01
Quốc Hùng và nnk., 2017). Loại tai biến này đang là một vấn đề được sự quan tâm đặc biệt của các nhà quản lý, trường đại học và viện nghiên cứu của nhiều quốc gia trên thế giới.

Việt Nam là một trong số những quốc gia nằm trong khu vực thường xuyên bị ảnh hưởng của sạt lở đất do khí hậu nhiệt đới ẩm gió mùa và địa hình đồi núi khá nhiều. Trong bối cảnh biến đổi khí hậu toàn cầu đang diễn ra ngày càng nghiêm trọng thì sạt lở đất, lũ ống, lũ quét xuất hiện nhiều hơn. Theo nghiên cứu của Lê Quốc Hùng và nnk. (2017), 

hầu như năm nào ở nước ta vào mùa mưa cũng xảy ra sạt lở đất, gây thiệt hại lớn về người và tài sản. Tại Việt Nam, đã có nhiều nghiên cứu về sạt lở đất, trong đó phải kể đến là: Nghiên cứu nguy cơ và phân vùng nhạy cảm trượt lở đất khu vực hồ thủy điện Sơn La (Trần Anh Tuấn và Nguyễn Tứ Dần, 2012), một nghiên cứu khác của tác giả Trần Thanh Hà (2013) đã nghiên cứu mối quan hệ giữa địa mạo và trượt lở đất khu vực Lào Cai. Dự báo nguy cơ trượt lở huyện Xín Mần, Hà Giang của Đỗ Minh Ngọc và nnk. (2016). Trong các nghiên cứu, đề án điều tra, phân vùng cảnh báo nguy cơ trượt lở đất đá ở các vùng miền núi của Lê Quốc Hùng (2012-2015) là một nghiên cứu khá công phu và đã đưa ra được một số bản đồ cảnh báo nguy cơ trượt lở đất (Lê Quốc Hùng và nnk., 2017). Các nghiên cứu kể trên chủ yếu xác định và cảnh báo trượt lở đất bằng một số phương pháp địa chất, trong đó bản đồ phân bố trượt lở đất thường được thành lập bằng phương pháp điều tra trực tiếp ở thực địa kết hợp với giải đoán ảnh hàng không, hoặc ảnh vệ tinh quang học.

Từ những năm đầu của thế kỷ XXI, các nhà khoa học trên thế giới đã đi sâu nghiên cứu vấn đề trượt lở đất và đã công bố nhiều công trình nghiên cứu có giá trị về lĩnh vực này (Lee và Min, 2001; Lee và nnk., 2002; Lee và Dan, 2005). Trong đó, nhiều công trình đã sử dụng các tư liệu viễn thám vào việc xác định các điểm trượt lở đất, các yếu tố có ảnh hưởng đến quá trình trượt lở đất như các đới phá hủy kiến tạo, hiện trạng lớp phủ thực vật,... Công nghệ viễn thám hiện nay đã trở thành một công cư hữu ích trong xác định trượt lở đất vì nó cung cấp một cái nhìn tổng hợp và có thể được lặp lại ở nhiều thời điểm khác nhau. Đặc biệt, phép đo giao thoa Radar độ mở tổng hợp (Synthetic Aperture Radar - SAR) là phương pháp đánh giá những thay đổi trên bề mặt trái đất đã được ứng dụng từ khoảng 20 năm nay (Tran Van Anh và nnk., 2015; 2016). Giao thoa Radar (Differential SAR Interferometry - DInSAR) là phương pháp sử dụng ít nhất hai ảnh ở hai thời điểm trước và sau khi có sự thay đổi về địa hình để tìm ra sự dịch chuyển bằng cách đo độ lệch pha của hai chu kỳ thu ảnh (Tran Van Anh và nnk., 2007). Tuy nhiên, phương pháp này có nhiều hạn chế đó là không loại bỏ được một số ảnh hưởng như: khí quyển, đặc tính tán xạ của các đối tượng trên bề mặt,... Để khắc phục những hạn chế của phương pháp DInSAR thì phương pháp PSI được đề xuất bởi
Ferretti và nnk. (2001), dựa trên việc sử dụng một loạt ảnh SAR đa thời gian cùng một vị trí để chiết tách ra một số điểm có tán xạ phản hồi cố định (Persistent scatterer, PS) và từ đó xác định được các biến động địa hình. Phương pháp PSI từ đó đã dần thay thế phương pháp DInSAR truyền thống, tuy nhiên vẫn còn có những hạn chế là khi khu vực nghiên cứu có nhiều thực phủ thì số lượng điểm PS cũng ít (Tran Van Anh và nnk., 2016). Để tăng số lượng điểm tán xạ cố định, một số phương pháp khác đã được phát triển như STAMPS Stanford (Hooper và nnk., 2010), Small Baseline (phương pháp đường đáy ngắn) (Berardino và nnk., 2002). Kỹ thuật SAR giao thoa đa thời gian đã cho thấy khả năng cung cấp thông tin về biến dạng mặt đất trên các khu vực rộng có độ chính xác đạt tới milimet (Ferretti và nnk., 2001). Phương pháp này phù hợp với các cuộc khảo sát ở những khu vực có địa hình thực phủ nhiều và độ dốc cao. Đặc biệt, với kho lưu trữ ảnh SAR rất lớn tạo cho việc xử lý chuỗi ảnh SAR cho mục đích giám sát các biến đổi địa hình trong quá khứ rất thuận lợi. Ngoài ra, hiện nay có một số ảnh SAR được cung cấp miễn phí cũng là một nguồn ảnh hưu ích cho các nghiên cứu về biến động địa hình nói chung và trượt lở đất nói riêng.

Trong nghiên cứu này, phương pháp đường đáy ngắn SBAS đã được ứng dụng để xác định trượt lở đất khu vực huyện Bát Xát, tỉnh Lào Cai với loại ảnh ALOS PalSAR-1. Phương pháp này không yêu cầu số lượng ảnh được sử dụng quá nhiều và bên cạnh đó các cặp ảnh cũng được tối ư hơn với khoảng cách đường đáy ảnh theo không gian và thời gian được lựa chọn ngắn nhất giúp giảm các sai số do mất tương quan.

\section{Dữ liệu và phương pháp nghiên cứu}

\subsection{Khu vực nghiên cứu}

Khu vực nghiên cứu nằm chủ yếu ở huyện Bát Xát và một phần của huyện $\mathrm{Sa} \mathrm{Pa}$, thuộc tỉnh Lào Cai (Hình 1). Bát Xát nằm ở phía tây bắc tỉnh Lào Cai, phía tây bắc và đông bắc giáp tỉnh Vân Nam (Trung Quốc), phía tây giáp huyện Phong Thổ (Lai Châu), phía nam là huyện Sa Pa và thành phố Lào Cai, phía đông nam là thành phố Lào Cai.

Toàn bộ nền địa hình Bát Xát được kiến tạo bởi nhiều dải núi cao, nổi bật là hai dải núi chính tạo nên các hợp thuỷ: suối Ngòi Phát, suối Lũng Pô, suối Quang Kim. Địa hình cao dần, điểm cao nhất 


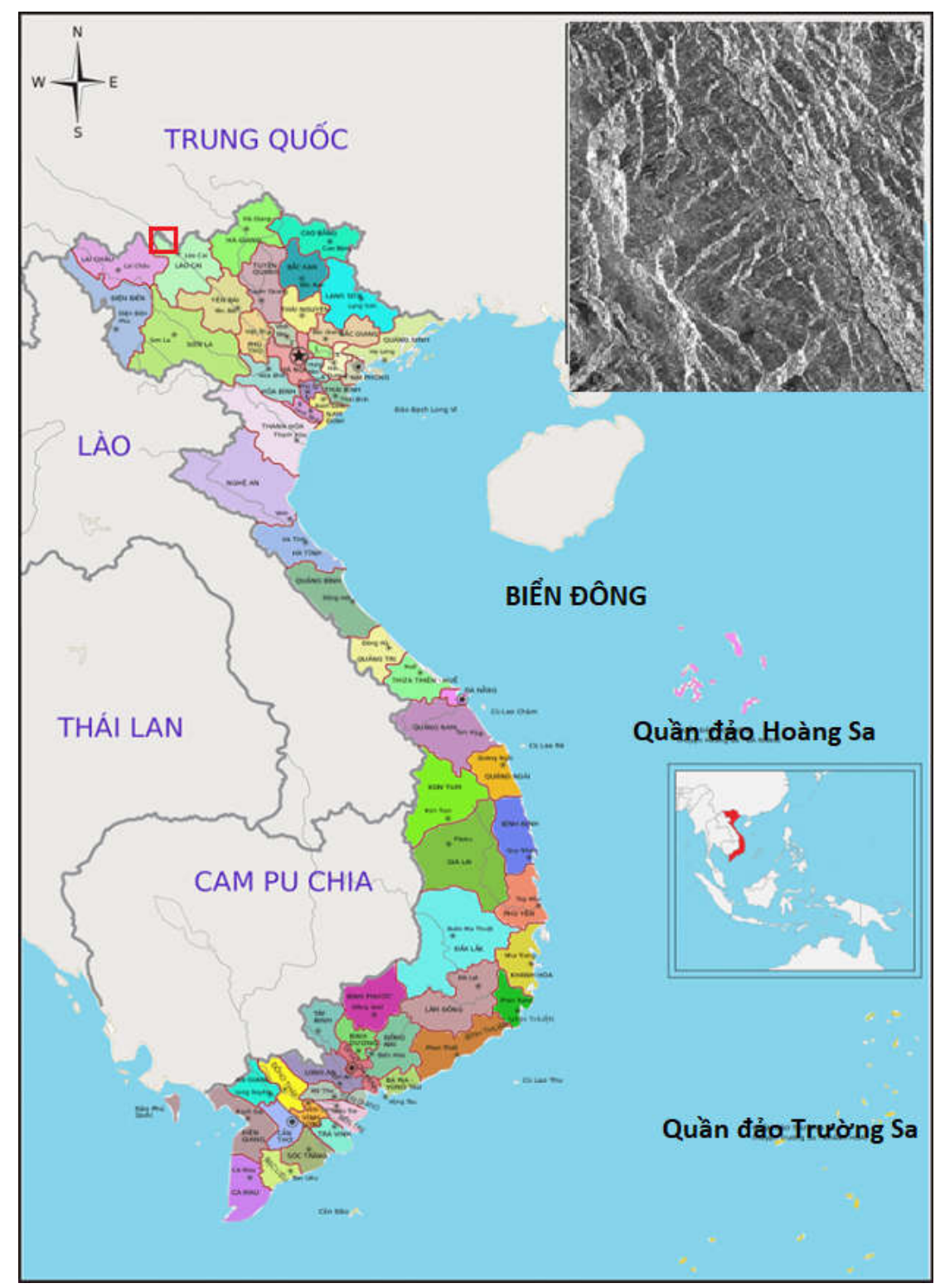

Hình 1. Khu vực thực nghiệm trên bản đồ Việt Nam và khung ảnh ALOS PaISAR.

có độ cao 2945 m, điểm thấp nhất có độ cao 88 m (Hoàng Trung Thông, 2016).

Kiến tạo địa hình khu vực nghiên cứu có đặc điểm là vùng núi cao có độ chia cắt lớn, thung lũng hẹp khe sâu, độ dốc lớn. Hàng năm từ tháng 7 đến tháng 9 là khoảng thời gian mưa nhiều, thường xảy ra trượt lở đất và lũ quét cho các khu vực miền núi Việt Nam, trong đó huyện Bát Xát và xã Trung Chải thuộc huyện $\mathrm{Sa}$ Pa là điểm nóng của trượt lở đất. Theo nghiên cứu của Lê Quốc Hùng và nnk. (2017), xã Phìn Ngan, xã Quang Kim hay tại quốc lộ 4D là những nơi thường xuyên bị trượt lở đất.

\subsection{Dũ liệu nghiên cúu}

Trong nghiên cứu này, 13 cảnh ảnh ALOS PalSAR với quỹ đạo đi lên, độ phân giải không gian là $16 \mathrm{~m}$ đã được sử dụng. Bộ dữ liệu sử dụng hình ảnh với đường quét là 478 và hàng quét là 440 tạo thành tập hợp dữ liệu trong khoảng thời gian ba năm, từ tháng 8 năm 2007 đến tháng 11 năm 2010. Bảng 1 là thông tin tập hợp dữ liệu của ALOS PalSAR kiểu phân cực đôi (FBD) gồm $\mathrm{HH}$ và $\mathrm{HV}$, mức xử lý 1.1. Trong nghiên cứu liên quan đến tạo giao thoa thì phân cực $\mathrm{HH}$ là phù hợp, do vậy việc tiền xử lý đầu tiên sẽ là tách ra phân cực HH. Bên cạnh đó mô hình số độ cao SRTM với độ phân giải 
90 m được sử dụng để loại bỏ pha địa hình và hiệu chỉnh về hệ tọa độ địa lý VN2000 của khu vực Việt Nam.

Bảng 1. Thông tin về tập dũ liệu.

\begin{tabular}{|c|c|c|c|}
\hline TT & Ngày thu ảnh (Y/M/D) & Kiểu ảnh & Quỹ đạo \\
\hline 1 & $2007 / 08 / 10$ & FBD & Đi lên \\
\hline 2 & $2007 / 09 / 25$ & FBD & Đi lên \\
\hline 3 & $2007 / 11 / 10$ & FBD & Đi lên \\
\hline 4 & $2008 / 05 / 12$ & FBD & Đi lên \\
\hline 5 & $2008 / 06 / 27$ & FBD & Đi lên \\
\hline 6 & $2008 / 08 / 12$ & FBD & Đi lên \\
\hline 7 & $2009 / 06 / 30$ & FBD & Đi lên \\
\hline 8 & $2009 / 08 / 15$ & FBD & Đi lên \\
\hline 9 & $2009 / 09 / 30$ & FBD & Đi lên \\
\hline 10 & $2010 / 07 / 03$ & FBD & Đi lên \\
\hline 11 & $2010 / 08 / 18$ & FBD & Đi lên \\
\hline 12 & $2010 / 10 / 03$ & FBD & Đi lên \\
\hline 13 & $2010 / 11 / 18$ & FBD & Đi lên \\
\hline
\end{tabular}

\subsection{Phương pháp nghiên cứu}

Việc sử dụng kỹ thuật giao thoa Radar (InSAR) để đo bề mặt trái đất, bao gồm các bề mặt địa hình và biến dạng địa hình, đã được chứng minh thành công trong hai thập kỷ qua. Phương pháp giao thoa truyền thống cho phép tạo ra các hình ảnh giao thoa của các pha dịch chuyển giữa hai hoặc ba hình ảnh thu được trong những thời điểm khác nhau trên cùng một khu vực. Phương trình (1) minh họa pha biến dạng bề mặt đất được đề xuất bởi Gabriel và nnk. (1989).

Giả thiết rằng nếu có sẵn một pha của mô hình số độ cao DEM, $\varphi_{\text {Topo }}$ được mô phỏng và được loại bỏ đi từ pha giao thoa tổng hợp $\Delta \varphi_{\text {Int }}$ thì ta sẽ thu được pha của biến động địa hình (DInSAR) $\Delta \varphi_{D-I n t}$ công thức (1):

$$
\Delta \varphi_{D-I n t}=\Delta \varphi_{\text {Int }}-\varphi_{\text {Topo }_{\text {simu }}}=\varphi_{\text {Displ }}
$$

Trong đó: $\varphi_{\text {Toposimu }}$ - thành phần địa hình mô phỏng, có chứa thành phần pha phẳng. Lưu ý rằng các quỹ đạo ảnh hưởng đến thành phần địa hình mô phỏng, ngay cả khi quá trình làm phẳng không được thực hiện một cách rõ ràng. Công thức (1) tóm tắt nguyên lý của DInSAR, cho phép xác định các dịch chuyển của địa hình được tạo ra từ hai ảnh SAR phức.

Công thức (1) đại diện cho một phương trình xác định biến động địa hình từ DIsSAR đơn giản. Để biểu diễn đầy đủ mối quan hệ giữa pha địa hình và biến động địa hình thì công thức (2) được biểu diễn:

$$
\begin{aligned}
\Delta \varphi_{\text {D-Int }}=\Delta \varphi_{\text {Int }}-\varphi_{\text {Topo }_{\text {stimu }}} \\
=\varphi_{\text {Displ }}+\varphi_{\text {Topo }_{\text {res }}} \\
+\varphi_{\text {Atm }_{s}}-\varphi_{\text {Atm }_{M}}+\varphi_{\text {Orb }_{s}} \\
-\varphi_{\text {Orb }_{M}}+\varphi_{\text {Noise }}+2 . k . \pi
\end{aligned}
$$

Trong đó: $\varphi_{\text {Topores }}$ - thành phần sai số tồn dư; $\varphi_{A t m}$ - thành phần pha khí quyển ở thời điểm thu được của mỗi cảnh ảnh; $\varphi_{\text {Orb }}$ - thành phần pha do các lỗi quỹ đạo của mỗi cảnh ảnh; $\varphi_{\text {Noise }}$ - pha nhiễu, $k$ - giá trị số nguyên lần của pha (Zebker và nnk., 1997)

Mục đích của bất kỳ kỹ thuật nào của DInSAR là lấy được $\varphi_{\text {Displ }}$ từ $\Delta \varphi_{D_{-} I n t}$. Điều này đồng nghĩa với việc tách $\varphi_{\text {Displ }}$ từ các thành phần pha khác của phương trình số (2). Một điều kiện cần thiết để thực hiện việc phân chia này là để phân tích các điểm ảnh có nhiễu $\varphi_{\text {Noise }}$, thường liên quan đến hai tán xạ: những nơi phản hồi Radar bởi những vật thể phản chiếu mạnh và không đổi theo thời gian được gọi là tán xạ cố định (PS) và những phản hồi không đổi theo thời gian, nhưng là do các đối tượng phân tán nhỏ khác nhau (Distribatter Scatterers - DS). Những hạn chế chính của DInSAR bao gồm: (i) sự tương quan về thời gian và hình học có ảnh hưởng đến thành phần $\varphi_{\text {Noise }}$ (Hanssen và Feijt, 1997); (ii) việc giải mở pha liên quan đến ước tính giá trị $\mathrm{k}$ (Ghiglia và Pritt, 1998); và (iii) thành phần khí quyển (Zebker và nnk., 1997). PSI là đại diện cho một phương pháp của công nghệ SAR giao thoa, khai thác nhiều hình ảnh SAR thu được trên cùng một khu vực, các quy trình xử lý và phân tích dữ liệu thích hợp để tách riêng $\varphi_{\text {Displ }}$ từ các thành phần pha khác được mô tả trong công thức (2).

Phương pháp đường đáy ngắn (SBAS) ban đầu được đề xuất bởi (Berardino và nnk., 2002). SBAS được sử dụng để phân tích các mục tiêu tán xạ phân tán DS và tán xạ cố định PS. Kết quả đầu ra giống với các kết quả được tạo ra trong phân tích giao thoa DInSAR, nhưng chúng có liên quan đến chuỗi thời gian SAR lớn thay vì chỉ liên quan đến hai cảnh ảnh (tối đa là 4 cảnh ảnh trong phương pháp DInSAR). Đối với quá trình xử lý PS, cách tiếp cận SBAS ít nhạy cảm hơn với số lượng ảnh đầu vào, vì SBAS khai thác tương quan phân bố không gian thay vì dựa trên giá trị điểm ảnh; hơn nữa trong SBAS một số giả định được thực hiện trên mối tương quan với các điểm biến dạng địa hình. 
Tuy nhiên, trong trường hợp này, khi có càng nhiều dữ liệu đầu vào thì cho kết quả đầu ra càng tốt vì thành phần khí quyển trong pha giao thoa có thể được ước tính và loại bỏ tốt hơn khi có nhiều thời kỳ ảnh.

Phương pháp này nhằm mục đích giảm thiểu sự phân cách trong cả miền thời gian và phạm vi tần số Doppler của cặp ảnh thu nhận để tăng mối tương quan giữa các cặp giao thoa. Hooper và nnk. (2010) đã phát triển một phương pháp lọc pha tương quan thấp cho các khoảng thời gian giãn cách ngắn. Do đó, các điểm ảnh lọc bị cô lập bởi các điểm ảnh liên quan có thể được xác định để xử lý.

\section{Kết quả nghiên cứu và thảo luận}

Bằng cách kết hợp các cảnh ảnh ở các thời điểm khác nhau trong Bảng 1 và 12 cặp ảnh với đường đáy ngắn đã được tạo ra. Sự phân bố các đường đáy ảnh vuông góc và thời gian được biểu diễn trong Hình 2.

Việc xử lý giao thoa được thực hiện bằng phần mềm SARscape với pha địa hình được loại bỏ bằng cách sử dụng SRTM DEM.

Sau khi tiến hành xử lý để quan sát sự thay đổi độ trượt của các vị trí trên phạm vi tập hợp ảnh ALOS PalSAR khu vực Bát Xát và Sa $\mathrm{Pa}$, nhóm tác giả thấy rằng trượt trong khu vực này đang tiến triển khá nhanh. Hình 3 mô tả sự phát triển trượt lở đất trong suốt thời gian nghiên cứu. Lở đất lớn nhất trong giai đoạn này được hiển thị tại các vị trí trên hình ảnh được đánh dấu bằng hình elip trong mỗi hình. Trong kết quả đầu tiên (Hình 3a) sau 46 ngày quan sát, sự thay đổi rất nhỏ, màu xanh lam thể hiện mức độ trượt lở dưới $5 \mathrm{~cm}$ (bên trong elip). Trong kết quả thứ hai (Hình $3 b$ ) sau 2 lần quan sát, trượt lở đất bắt đầu mạnh hơn lần đầu tiên, tốc độ trượt tối đa khoảng $10 \mathrm{~cm}$ mỗi năm. Sau 3 năm quan sát (Hình 4f), trượt lở đất xảy ra không chỉ ở vị trí đánh dấu mà còn ở nhiều vị trí khác. Sáu số liệu trong Hình 3 chỉ biểu hiện một loạt các kết quả cho thấy các vụ lở đất khác nhau trên khu vực nghiên cứu. Trượt lớn nhất tổng cộng khoảng $150 \mathrm{~cm}$ tại khu vực này. Lấy trung bình 3 năm kết quả xử lý, tỷ lệ trượt lở đất trung bình lớn nhất khoảng $50 \mathrm{~cm}$ mỗi năm tại các vị trí như Tả Giàng Phìn, Dền Sáng, Trung Chải, Phìn Ngan.

Bản đồ các địa điểm khảo sát lở đất được thực hiện bởi Viện Khoa học Địa chất và Khoáng sản vào năm 2013 (Lê Quốc Hùng và nnk., 2017). Những điểm được đánh dấu hình tam giác màu xanh (Hình 4) là vị trí các điểm khảo sát trượt lở và giải đoán trượt lở từ ảnh hàng không khu vực Lào Cai. Trong khu vực được đánh dấu Tả Giàng Phìn, Phìn Ngan, Trung Chải là các khu vực có sạt lở đất lớn nhất với vị trí trượt phù hợp với các điểm đánh dấu.

Các điểm khảo sát trượt lở đất được làm năm 2013 và các điểm giải đoán trượt lở lại được làm từ ảnh hàng không chụp năm 2003 (Lê Quốc Hùng, 2017) còn ảnh vệ tinh lại trong giai đoạn 2007-2010. Tuy nhiên, dữ liệu ảnh ALOS PalSAR cũng đánh giá được khả năng xác định trượt lở đất khi có khá nhiều điểm tương đồng tại các điểm đánh dấu.

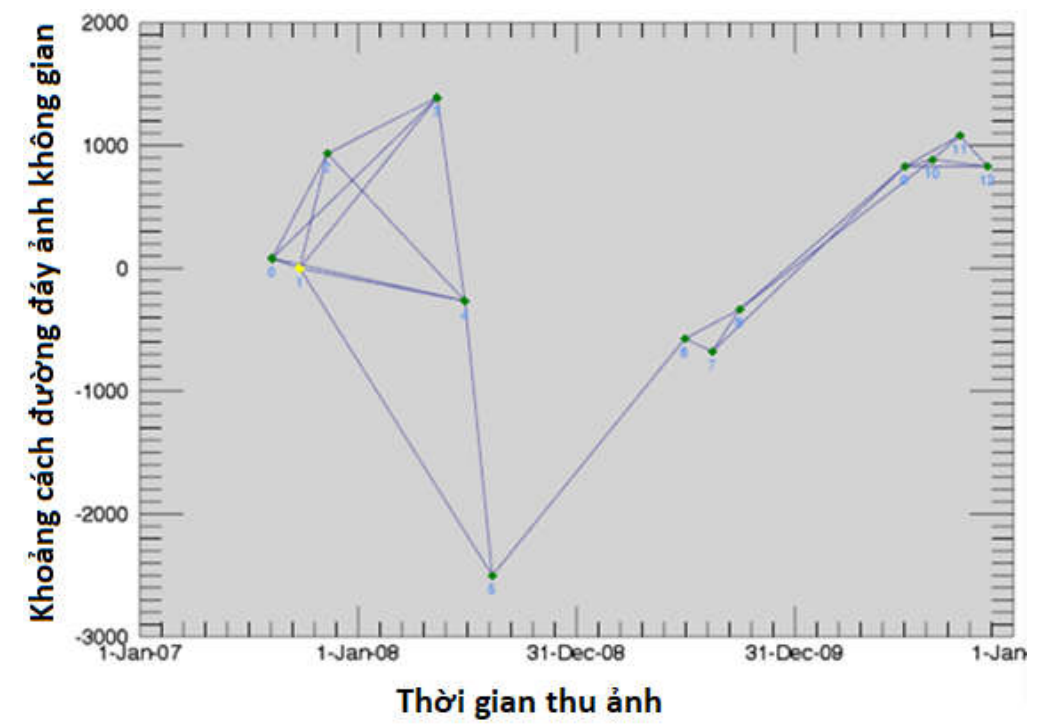

Hình 2. Khu vực thực nghiệm trên bản đồ Việt Nam và khung ảnh ALOS PalSAR. 

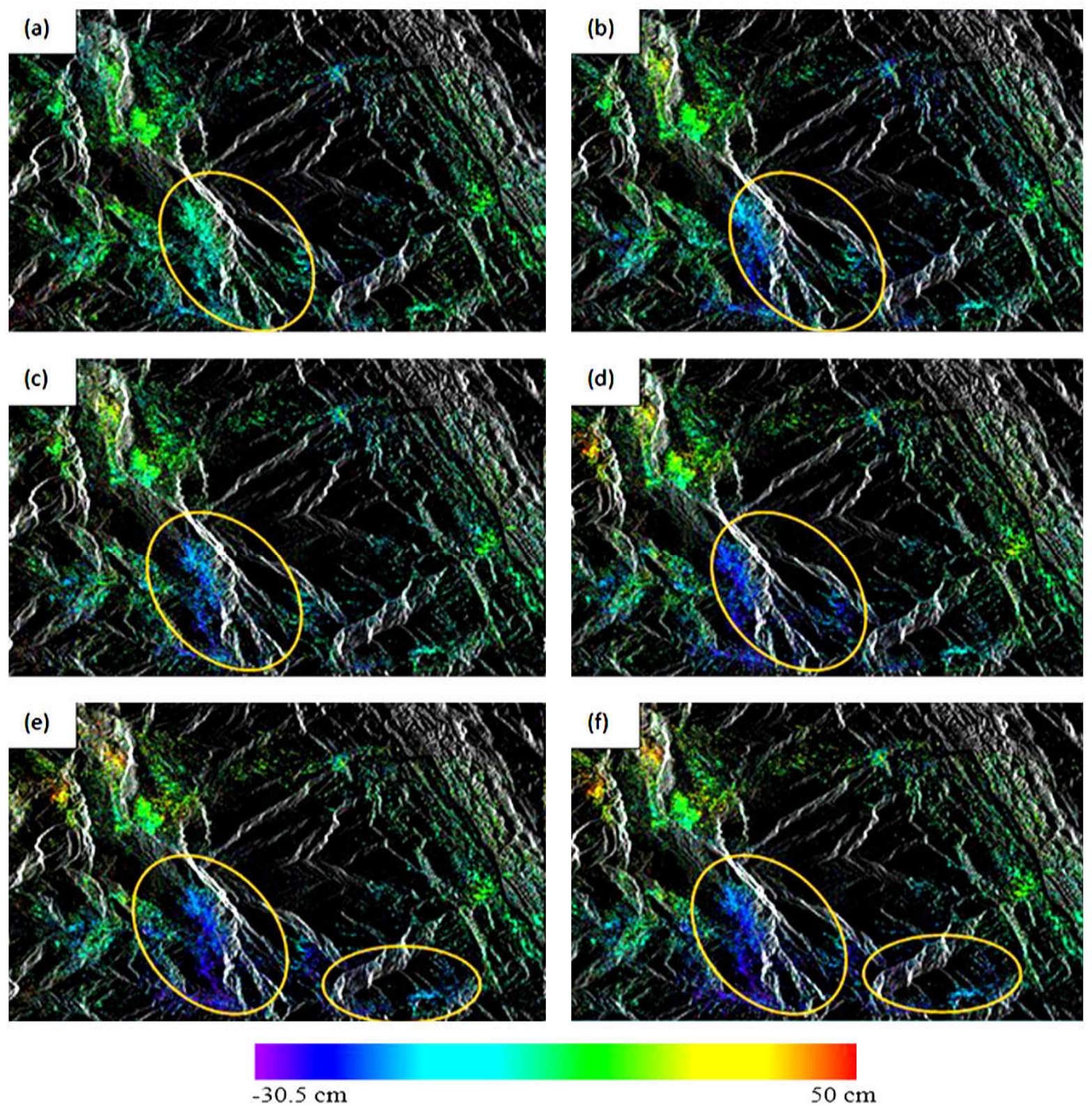

Hình 3. Sạt lở đất ở giai đoạn 2007-2010.

(a) Thò̀i gian giứa 10/8/2007 và 25/9/2007; (b) 25/9/2007 và 10/11/2007; (c) 5/12/2008 và 27/6/2008; (d) 8/12/2008 và 30/6/2009; (e) 15/8/2009 và 3/7/2010; (f) 3/7/2010 và 11/11/2010.

Tại điểm cầu Móng Sến, xã Trung Chải (trung tâm hình elip góc phải Hình 4) đã có điểm khảo sát trùng khít với các điểm trượt xác định từ ảnh. Tại điểm này khối trượt Mống Sến đã hình thành từ khá lâu và đến bây giờ vẫn tiếp tục trượt (Nguyễn Bá Duẩn và nnk., 2011; Trần Thanh Hà, 2013). Hình 5 là bản đồ các vị trí trượt lở được làm từ ảnh Radar ALOS PalSAR-1 trong giai đoan 2007-2010 được đưa lên nền của bản đồ hành chính và đường giao thông. Các vị trí trượt nằm sát đường giao thông khá nhiều, đặc biệt trên quốc lộ 4D, điều này chứng minh do tác động của con người khi mở rộng taluy đường thường gây nên trượt lở đất. Theo tài liệu báo cáo khảo sát của Lê Quốc Hùng và nnk. (2017) thì trong số 88 điểm trượt tại huyện Bát Xát đã được khảo sát thì chỉ có 9 điểm là nằm trên sườn tự nhiên còn lại 79 điểm nằm trên các taluy đường. Điều này chứng tỏ rằng các điểm phân bố trượt lở xác định từ chuỗi ảnh ALOS PalSAR là hợp lý. 



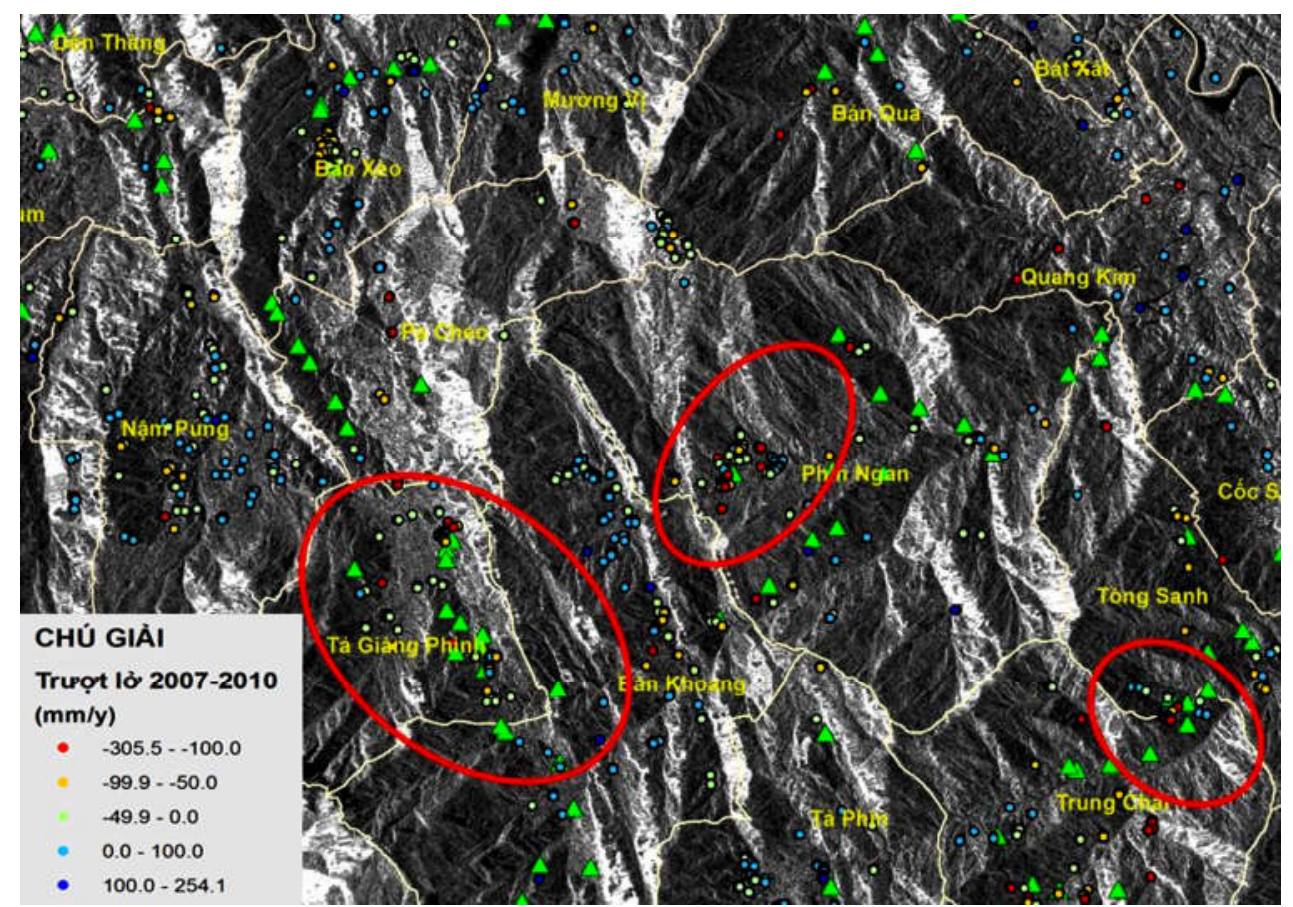

Hình 4. Trượt lở đất trung bình trong giai đoạn 2007-2010 bằng ảnh Radar,

( $\triangle$ là điểm khảo sát trượt lở do viện Khoa học Địa chất và Khoáng sản cung cấp).

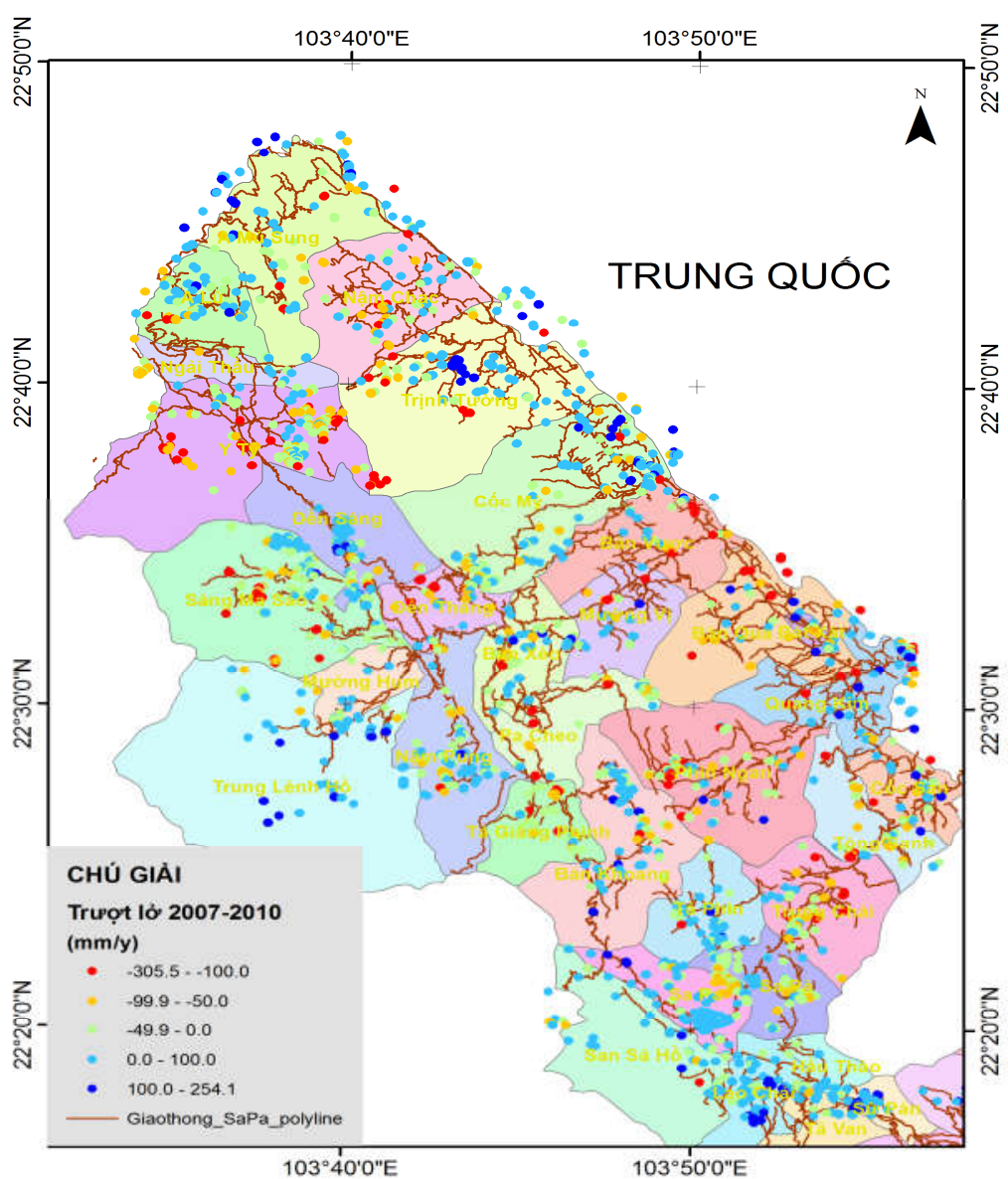

Hình 5. Bản đồ vị trí các điểm trượt lở trung bình khu vụ̂c Bát Xát, tỉnh Lào Cai, giai đoạn 2007-2010. 

Việc sử dụng ảnh vệ tinh ALOS PalSAR-1 với kênh ảnh $L$ có bước sóng dài $(23,5 \mathrm{~cm})$, có khả năng xuyên qua các khu vực có thực phủ đã làm tăng khả năng xác định được các vị trí bị trượt lở đất, bị che khuất dưới tán cây, vì vậy loại ảnh này khá phù hợp với những khu vực miền núi có thực phủ dày đặc.

\section{Kết luận và khuyến nghị}

Với tập hợp dữ liệu gồm 13 ảnh ALOS PalSAR1 được thu trong khoảng thời gian từ 8/2007 đến tháng $11 / 2010$, phương pháp đường đáy ngắn SBAS đã được ứng dụng để xác định trượt lở cho khu vực huyện Bát Xát, tỉnh Lào Cai. Kết quả xác định các điểm trượt lở bằng phương pháp này đã được so sánh với các điểm khảo sát thực địa năm 2013 và giải đoán từ ảnh hàng không do Viện Khoa học Địa chất và Khoáng sản Việt Nam cung cấp. Các vị trí phân bố trượt lở tại các điểm như cầu Mống Sến, xã Trung Chải, xã Tả Giàng Phìn hay Phìn Ngan đều trùng với các điểm khảo sát. Điều này chứng minh rằng ảnh ALOS PalSAR với phương pháp SBAS là phù hợp cho xác định trượt lở khu vực miền núi.

Lần đầu tiên phương pháp đường đáy ngắn SBAS đã được áp dụng thành công cho xác định trượt lở đất khu vực miền núi như huyện Bát Xát, Sa Pa, tỉnh Lào Cai. Việc sử dụng ảnh vệ tinh Radar đa thời gian giúp hiểu rõ hơn và mô hình hóa tiến trình trượt lở đất. Ngoài ra, dựa trên dữ liệu ALSOS PaISAR hoặc các dũ liệu ảnh Radar khác thì có thể tính toán vận tốc trượt lở đất theo năm ở những thời điểm nhất định, ngay cả đối với các biến dạng rất nhỏ. Phương pháp SBAS không đòi hỏi nhiều ảnh như phương pháp PSInSAR, thêm vào đó, phương pháp này khắc phục một số hạn chế của PSInSAR, có được điểm PS nhiều hơn ở những nơi che phủ thực vật.

Tuy nhiên, phương pháp này cũng có một số hạn chế như khả năng xác định độ dịch chuyển địa hình với dữ liệu ALOS phụ thuộc nhiều vào sự lựa chọn của quỹ đạo phù hợp với khu vực nghiên cứu. Đối với các khu vực được che phủ bởi thảm thực vật dày đặc, không có điểm tán xạ cố định (PS) có thể được quan sát ở các thời điểm khác nhau hoặc kích thước điểm PS không đủ lớn để phản ánh được sự dịch chuyển hay thay đổi của địa hình thì lúc đó phương pháp SBAS không thể thực hiện được. Để khắc phục việc này thì điểm tán xạ nhân tạo nên được lắp đặt trong khu vực nghiên cứu, hoạt động như điểm PS và tín hiệu tán xạ của các điểm này là rất tốt cho xác định biến động địa hình.

\section{Lời cảm ơn}

Nhóm tác giả xin gửi lời cảm ơn do nhận được tư liệu từ đề tài mã số TNMT 2017.08.07: "Nghiên cứu cơ sở khoa học và đề xuất giải pháp sử dụng ảnh Radar đa thời gian trong giám sát biến động lớp phủ bề mặt và biến động địa hình phục vụ cho dự báo nguy cơ biến động địa hình khu vực miền núi Việt Nam", Bộ Tài nguyên và Môi trường Việt Nam.

\section{Tài liệu tham khảo}

Berardino, P., Fornaro, G., Lanari, R., Sansosti, E., (2002). A new algorithm for surface deformation monitoring based on small baseline differential SAR interferograms. IEEE Transactions on Geoscience and Remote Sensing 40 (11), 2375-2383.

Đỗ Minh Ngọc, Đặng Thị Thùy, Đỗ Minh Đức, (2016). Ứng dụng GIS và phương pháp phân tích thứ bậc (AHP) thành lập bản đồ nguy cơ trượt lở huyện Xín Mần, tỉnh Hà Giang, Việt Nam. VNU Journal of Science: Earth and Environmental Sciences 32 (2S), 206-216.

Ferretti A., Prati C., Rocca F., (2001). Permanent scatterers in SAR interferometry. IEEE Transactions on Geoscience and Remote Sensing 39 (1), 8-20.

Gabriel, A., K., Goldstein, R. M., Zebker, H. A., (1989). Mapping small elevation changes over large areas: Differential Radar interferometry. Journal of Geophysical Research: Solid Earth 94 (B7), 9183-9191

Ghiglia, D. C., Pritt, M. D., (1998). Two-dimensional phase unwrapping: theory, algorithms, and software 4. Wiley New York.

Hanssen R, Feijt A., (1997). A first quantitative evaluation of atmospheric effects on SAR interferometry. In: ERS SAR Interferometry, 277.

Hoàng Trung Thông, (2016). Đánh giá nguy cơ lũ quét tại huyện $\mathrm{SaPa}$, tỉnh Lào Cai. Luận văn thạc sỹ. Đại học Quốc gia Hà Nội. Việt Nam. 
Hooper, A., Spaans, K., Bekaert, D., Cuenca, M. C., Arlkan, M., Oyen, A., (2010). StaMPS/MTI manual. Delft Institute of Earth Observation and Space Systems Delft University of Technology. Kluyverweg 1, 2629.

Lê Quốc Hùng, Nguyễn Thị Hải Vân, Phạm Văn Sơn, Nguyễn Hoàng Ninh, Nguyễn Tâm, Nguyễn Thị Huyền, (2017). Landslide inventory mapping in the fourteen Northern provinces of Vietnam: achievements and difficulties. In: Workshop on World Landslide Forum. Springer, 501-510.

Lee S., Choi J., Min K., (2002). Landslide susceptibility analysis and verification using the Bayesian probability model. Environmental Geology 43 (1-2), 120-131.

Lee, S., Dan, N. T., (2005). Probabilistic landslide susceptibility mapping in the Lai Chau province of Vietnam: focus on the relationship between tectonic fractures and landslides. Environmental Geology 48 (6), 778-787.

Lee, S., Min, K., (2001). Statistical analysis of landslide susceptibility at Yongin, Korea. Environmental Geology 40 (9), 1095-1113.

Nguyễn Bá Duẩn, Đặng Thanh Hải, Vũ Đức Minh, Lê Thị Thúy Hiên, (2011). Nghiên cứu xác định nguyên nhân trượt lở khu vực cầu móng sến, tỉnh Lào Cai. Vietnam Journal of Earth Sciences 33 (2), 164-174.
Trần Anh Tuấn, Nguyễn Tứ Dần, (2012). Nghiên cứu nhạy cảm và phân vùng nguy cơ trượt lở đất khu vực hồ thủy điện Sơn La theo phương pháp phân tích cấp bậc Saaty. Tạp chí các khoa học về Trái đất 34(3), 223-232.

Trần Thanh Hà, (2013). Quan hệ giữa đặc điểm địa mạo và trượt lở đất tại tỉnh Lào Cai. $V N U$ Journal of Science: Earth and Environmental Sciences 29 (3), 35-44.

Tran Van Anh, Tran Quoc Cuong, Nguyen Duc Anh, Ho Tong Minh Dinh, Tran Trung Anh, Nguyen Như Hung, Luong Thi Thuy Linh, (2016). Application of PSInSAR method for determining of land subsidence in Hanoi city by Cosmo-Skymed imagery. GIS-IDEAS 2016. Hanoi, Vietnam.

Tran Van Anh, Masumoto, S., Raghavan, V., Shiono K., (2007). Spatial distribution of subsidence in Hanoi detected by JERS-1 SAR interferometry. Japan Society of Geoinformatics 18 (1), 3-13.

Tran Van Anh, Tran Quoc Cuong, Nguyen Duc Anh, Dang Vu Khac, (2015). Study of Subsidence detection by DinSAR and evaluation of some factors to the outcome. Vietnam Journal of Earth Sciences 37 (4), 344-354.

Zebker, H. A., Rosen, P. A., Hensley, S., (1997). Atmospheric effects in interferometric synthetic aperture Radar surface deformation and topographic maps. Journal of Geophysical Research: Solid Earth 102 (B4), 7547-7563. 